\title{
A MODEL TO MEASURE THE PERFORMANCE OF HUMAN RESOURCES IN ORGANISATIONS
}

\author{
Lecturer Magnolia Tilca PhD \\ "Vasile Goldiş" Western University of Arad \\ E-mail: tilca.magnolia@uvvg.ro \\ Elisabeta Mare \\ SMART APPS \& SOLUTIONS", Baia Mare, Romania \\ E - mail: sales@ smartapps.ro \\ Associate Professor Anca Apatean PhD \\ Technical University of Cluj - Napoca \\ E-mail: anca.apatean@gmail.com
}

(Received: December 2017; Accepted March 2018)

\begin{abstract}
The economic crisis, demography, technology, globalization etc. are all factors which will influence the organizational structures and business strategies. A new business strategy will require, among others, that passive Human Resources Management (HRM) change into an active one with a decisive influence upon business. The vision of an active HRM requires that HR information (IT) dedicated systems assist human resources managers in their decision-making. The existing IT systems predominantly manage the salary calculations and, possibly, the employee's professional development, two of the tasks that a human resources manager has to pursue. However, tasks such as assisting, consulting and engaging the human resources in the organization are equally important. IT systems must also develop into these directions. The present paper proposes a solution to measure the performance of human resources by creating an employee performance indicator (EPI). The paper first describes the economic phenomenon involved in the HR performance process, then the mathematical model is formulated, the algorithm is implemented, the solution of the model is analysed from a technical and economic point of view, and finally the decision is made. We use the weighted arithmetic mean to compute the EPI indicator and the correlation formula to establish the degree of relevance between the EPI indicator and the variables involved in the model. An implementation in $\mathrm{R}$ is given.

Key Words: ongoing performance management, key performance indicators, multiple linear regression, statistical $\mathrm{R}$ environment
\end{abstract}

J.E.L. CODES: C15, C60, M53

\section{Introduction}

Nowadays, performant information systems (IS) are able to assist almost the entire activity of an organisation: services, production, sales, customer management, 
Tilca M., Mare E., Apatean A. (2018)

A model to measure the performance of human resources in organisations

employees, management, decisions and so on. The new business strategies involve the human resources management (HRM) more and more in the decision process. It is about the performance management (PM) that consists in "all of the processes that managers use to effectively lead, mange, develop, reward and assess employees" (Garr, 2011).

Most existing HRM information systems are implemented to manage the salary calculations and only few of them manage the employee's professional development. In order to achieve performance management (PM), an ongoing supporting performance module was lately implemented in an HRM information system. This module is based on the continuous performance management principles and proved to be more efficiency than other performance management software: companies like Microsoft, Google, Adobe, PWC, Cargill and so on, who have recently (2012) adopted this kind of modules, increased their productivity and profits as a result of improving employees' performance.

Management information systems dedicated to ongoing performance management are in a continuous development. The managers are searching to improve the criteria of measuring employees' performance and the software developers are having difficulty finding the concrete formula that measures performance in various situations.

We propose a solution to measure the human resources performance by creating an employee performance indicator (EPI) based on the defined performance criteria of each job.

The first section describes some economic aspects regarding the efficiency of the HR process. In the second section, we give the mathematical solution of this efficiency process. We use the weighted arithmetic mean to compute the EPI indicator and the correlation formula to establish the degree of relevance between the EPI indicator and the variables involved in the model. The solution of the model is analysed from a technical and economic point of view and finally the decision is made. The model is implemented using $\mathrm{R}$ statistical environment.

\section{Preliminary notes}

In modern organisations, "performance management is management" (Garr, 2011). Many organisations treat performance management as a yearly event. Garr proposes an ongoing performance management framework which contains all of the activities included in a regular performance management, but the process is continuous. Garr's research shows that companies with an ongoing focus on performance management have better employees, talent and business results: $45 \%$ are more likely to have above-average financial performance and $46 \%$ are more 
Tilca M., Mare E., Apatean A. (2018)

A model to measure the performance of human resources in organisations

likely to be effective at holding costs at the same level or below the level of competitors.

In literary review, the topic of shifting the traditional performance management to continuous one is quite new and it is discussed by researchers and developers at different levels: Garr, analyst of the HR community of Bersin by Deloittes [1], designed a new Performance Management Framework to help HR organisations performance management from an event to a powerful ongoing business activity (Garr, 2011), Gandhi (Gandhi, 2017) underlines, in Chief Learning Officer [2], the importance of adopting an ongoing performance management; experts for IT developers sites, such as Atiim (A-team) [3], propose 10 tips for an Ongoing Performance Management Framework and their advantages (Atiim, 2017); Robertson, manager specialists of Step Two[4], talks about information management that it is not just a technology, but a business processes and practices that underpin the creation and use of information (Robertson, 2005), studies done by researchers from Brandon Hall Group (Brandon Hall Group, 2015) and so on.

Armstrong and Baron define performance management (PM) as "a strategic and integrated approach to delivering sustained success to organizations by improving the performance of the people who work in them and by developing the capabilities of teams and individual contributors." (Armstrong \& Baron, 1998) Ongoing performance management established the term "continuously" to "weekly", "daily".

The most compelling reasons are underlined by Hansen (Hansen, 2017): the annual review is inefficient, managers and employees need more feedback, ongoing feedback actually saves time, feedback is most effective when given in real-time, as it improves engagement and performance.

While performance management is asking "How do we manage the strategy we have put in place?" performance measurement asks "How do we track the progress of the strategy we've put in place?" Performance measurement "encompasses the assessment of performance and results achieved by individual employees, groups of employees or teams, and entire organizations" (OPM.gov, 2016). Performance measurement uses performance indicators. Performance Indicators (or Key Performance Indicators KPI) are the quantifiable masses, both financial and nonfinancial, of the performance of those tasks, operations or processes which are essential for business.

Tracked continuously and together with strategic objectives of the organisation, $H R$ performance indicators improve ongoing performance management. HR performance indicators generally measure employee engagement, performance ratings, retention/turnover, high potential employees (HIPO) [5], employees development plans, readiness for job, internal hire age, diversity of workforce, 
Tilca M., Mare E., Apatean A. (2018)

A model to measure the performance of human resources in organisations

level of competence and so on. Some HR performance indicators are quantifiable, while others are qualitative indicators. A glossary of employee performance indicators divided into key subject areas can be studied at the ICAEW's page (ICAEW, 2017).

Ongoing performance management in a human resource management context is "the supervision of an employee's work through one-to-one discussions and ongoing feedback from supervisors and regularly scheduled check-ins" (Rouse, 2016). In this regard, Performance Factors and Behaviour Indicators are intended to clarify for employees and supervisors what performance or behaviour is expected. There are described seven universal performance factors and four management performance factors (UC Riverside, 2016), with five rating levels for each factor: from exceptional to unsatisfactory performance. If employees clearly understand their assignments, know what level of performance is considered acceptable and receive consistent feedback then employees are successful performers. Technology is especially important in supporting the delivery of the necessary information regarding rated factors.

Technology is driving the evolution of ongoing performance management. The power of developing performant management information systems allowed big companies to implement their management activities regularly instead of sporadically. Thus, ongoing performance management could become part of the human resources' everyday role.

A human resource information system (HRIS) [6] is "a suite of software, databases and cloud computing which provide an all-encompassing solution for managing every aspect of a workforce" (Rietsema, 2016). HRISs include modules for classical human resources management like contact information, work progress, pay history, hours worked, benefit tracking and so on. Recently, HRISs were implemented for employee goal tracking which enable employees to set goals collaboratively (align with the organization), see in real time their progress and receive feedback from managers (see Clear Review software).

\section{Methodology section Problem framework}

As performance management systems are continuously developing, the present article proposes a model to measure the efficiency of human resources performance which may be implemented in HRIS.

Being known such evaluation criteria for employee that the number of achievements of the criterion may be determined, in order to evaluate the employee performance correlated with given criterion, we define the rate of appreciation as integer number between 0 and 100, less ratings meaning great appreciation, big 
Tilca M., Mare E., Apatean A. (2018)

A model to measure the performance of human resources in organisations

ratings meaning poor appreciation. Multiplying the number of achievements of each criterion with the rate of appreciation we obtain an evaluation of each criterion. Further, by assigning each criterion with the rate of the importance in criteria, we can compute the value of importance rate of the evaluation of each criterion. Finally, to determine the performance of an employee, we compute the weighted mean average of rate of the importance in criteria weighted by the evaluation of each criterion.

\section{The employee performance indicator EPI}

Definition 1. Being known $n$ evaluation criteria for employee and the number of achievements of each criterion $k_{i}, i=1, \ldots, n$, the employee performance indicator is defined as weighted mean average

where

$$
\text { (1) } E P I=\frac{\sum_{i=1}^{n} v_{i} \cdot p_{i}}{\sum_{i=1}^{n} p_{i}}
$$

- $\quad p_{i}:=k_{i} \cdot r_{i}, i=1, \ldots, n$ is the evaluation of each criterion with

○ $k_{i}, i=1, \ldots, n$ denotes the number of achievements of each criterion (an integer positive number) and

- $\quad r_{i}, i=1, \ldots, n$ denotes the rate of appreciation (a number between 0 and 100 , less ratings meaning great appreciation, big ratings meaning poor appreciation),

- $\quad v_{i}, i=1, \ldots, n$ is the rate of the importance in criteria (a real positive number between 0 and 10).

Observation 1. The formula (1) has sense as denominator is not null. Indeed, the case of all achievements to be zero $\left(k_{i}=0, \forall i=1, \ldots, n\right)$ is excluded, not being a real case.

Proposition 1. The employee performance indicator EPI takes real values between 0 and 10.

\section{Proof:}

We have following inequalities:

(2) $0 \leq k_{i} \leq \max (k), \forall i=1, \ldots, n$, where $k_{i} \in \mathrm{N}$

(3) $0 \leq r_{i} \leq 100, \forall i=1, \ldots, n$, where $r_{i} \in \mathrm{N}$

(4) $0 \leq v_{i} \leq 10, \forall i=1, \ldots, n$, where $v_{i} \in \mathbf{R}$

Multiplying inequalities (2) and (3) we have 
Tilca M., Mare E., Apatean A. (2018)

A model to measure the performance of human resources in organisations

$0 \leq p_{i} \leq 100 \cdot \max (k), \forall i=1, \ldots, n$, where $p_{i}:=k_{i} \cdot r_{i} \in N$.

Thus

(5) $0 \leq \sum_{i=1}^{n} p_{i} \leq 100 \cdot n \cdot \max (k)$ or

(6) $0 \leq \sum_{i=1}^{n} p_{i} \cdot v_{i} \leq 1000 \cdot n \cdot \max (k)$.

Dividing (6) and (5) and taking into account Observation 1, $0 \leq \frac{\sum_{i=1}^{n} p_{i} \cdot v_{i}}{\sum_{i=1}^{n} p_{i}} \leq 10$.

Observation 2.

a. If all the importance rates are equal, then EPI has the value of importance rate.

$b$. If the importance rates have the same value, 10, then EPI has maximum value.

Proof. Indeed, if $v_{1}=\ldots=v_{n}=v$ then $E P I=\frac{\sum_{i=1}^{n} v_{i} p_{i}}{\sum_{i=1}^{n} p_{i}}=v$. If the manager establishes the entire importance rate to be 10 , or 0 , then EPI has the maximum value, 10 , respectively the minimum value, 0 .

\section{EPI's applicability}

To illustrate the applicability of the EPI indicator we take a very simple example. Consider the training program of employees, a mandatory program in any organization. Human resources managers determine when training is necessary and the type of training necessary to improve performance and productivity. Human resource managers are responsible for conducting the training program.

Consider the set of 3 criteria on tracking the training progress of an employee:

- C1: the number of courses employee attended

- $\mathrm{C} 2$ : the number of graduated courses

- C3: the number of absences from courses

For a certain employee, there are known the number of achievements for each criterion:

- $\mathrm{k}_{1}=6$ courses attended 
Tilca M., Mare E., Apatean A. (2018)

A model to measure the performance of human resources in organisations

- $\mathrm{k}_{2}=4$ courses graduated

- $\mathrm{k}_{3}=1$ absence

The manager previous appreciates each criterion as follows:

- $r_{1}=20$

- $r_{2}=30$

- $r_{3}=50$

The manager previous sets the rate of importance in criteria:

- $\mathrm{v}_{1}=8$

- $\mathrm{v}_{2}=10$

- $\mathrm{v}_{3}=2.5$

Applying formula (1), the employee performance indicator has the value

$$
E P I=\frac{8(6 \cdot 20)+10(4 \cdot 30)+2.5(1 \cdot 50)}{6 \cdot 20+4 \cdot 30+1 \cdot 50}=7.88
$$

A score of 7.88 indicates that employee successfully meets performance expectations.

Now, considering the case when all the courses are graduated $\left(k_{2}=6\right)$ and there is no absence $\left(k_{3}=0\right)$, in the same rating values, the EPI is 9.2 that means the employee made an exceptional performance.

On the other side, if employee graduated only one course $\left(k_{2}=1\right)$ and gets 8 absences $\left(k_{3}=8\right)$, EPI is 4.08 that means the performance needs improvement.

\section{EPI's interpretation}

- Rating scale

EPI measures the performance of employee. The feedback is based on the following rating scale: an EPI rated between 10 and 9 means an exceptional performance, between 9 and 8 the employee exceeds performance expectations, between 8 and 7 the employee successfully meets performance expectations, a rate between 7 and 5 means that the performance needs improvement, a rate between 5 and 1 denotes an unsatisfactory performance.

- The strength of the association between the EPI indicator and the variables involved in the model

EPI indicator depends on three sets of variables: number of achievements, rate of appreciation and rate of importance of each criterion. Because each variable contains $n$ values, the total number of independent variables is $n \times 3$. Thus a multiple linear regression is necessary to apply.

Multiple linear regression is a statistical tool that examines how multiple independent variables are related to a dependent variable.

The independent variables are the $n \times 3$ variables involved in the EPI definition: 
Tilca M., Mare E., Apatean A. (2018)

A model to measure the performance of human resources in organisations

- the number of achievements: $k_{1}, k_{2}, \ldots, k_{n}$

- the rate of appreciation: $r_{1}, r_{2}, \ldots, r_{n}$

- the rate of importance of each criterion: $v_{1}, v_{2}, \ldots, v_{n}$

Proposition 2. The equation of linear multiple regression is

$$
\begin{aligned}
y_{E P I}=\beta_{0} & +\beta_{1,1} \cdot x_{k_{1}}+\beta_{1,2} \cdot x_{k_{2}}+\ldots+\beta_{1, n} \cdot x_{k_{n}}+ \\
& +\beta_{2,1} \cdot x_{r_{1}}+\beta_{2,2} \cdot x_{r_{2}}+\ldots+\beta_{2, n} \cdot x_{r_{n}}+ \\
& +\beta_{3,1} \cdot x_{v_{1}}+\beta_{3,2} \cdot x_{v_{2}}+\ldots+\beta_{3, n}+\varepsilon
\end{aligned}
$$

where

- $\quad x_{k_{1}}, \ldots, x_{k_{n}}, x_{r_{1}}, \ldots, x_{r_{n}}, x_{v_{1}}, \ldots, x_{v_{n}}$ are the independent variables corresponding to the number of achievements, the rates of appreciation, respectively the rates of the importance;

- $y_{E P I}$ is the dependent variable corresponding to EPI;

- $\quad \beta_{0}$ is the intercept;

- $\quad \beta_{i, j}, i=1,2,3, j=1, \ldots, n$ are the regression coefficients;

- $\varepsilon$ is the residual standard deviation.

Proposition 3. Knowing data for the independent variables $X$ collected from $N$ subjects and $N$ observations for the dependent variable $Y$, equation (7) becomes

(7) $Y=\beta \cdot X+\varepsilon$.

The regression coefficients are obtained as $\beta=\left(X^{T} X\right)^{-1} X^{T} Y$, (Hervé, 2007) where

- $Y=\left[\begin{array}{lllll}y_{1} & y_{2} & y_{3} & \ldots & y_{N}\end{array}\right]^{T}$

- $\varepsilon=\left[\begin{array}{lllll}\varepsilon_{1} & \varepsilon_{2} & \varepsilon_{3} & \ldots & \varepsilon_{N}\end{array}\right]^{T}$

$X=\left[\begin{array}{ccccccccccccc}1 & x_{1, k_{1}} & x_{1, k_{2}} & \ldots & x_{1, k_{n}} & x_{1, r_{1}} & x_{1, r_{2}} & \ldots & x_{1, r_{n}} & x_{1, v_{1}} & x_{1, v_{2}} & \ldots & x_{1, v_{n}} \\ 1 & x_{2, k_{1}} & x_{2, k_{2}} & \ldots & x_{2, k_{n}} & x_{2, r_{1}} & x_{2, r_{2}} & \ldots & x_{2, r_{n}} & x_{2, v_{1}} & x_{2, v_{2}} & \ldots & x_{2, v_{n}} \\ \ldots & \ldots & & & & & & & & & & & \\ 1 & x_{N, k_{1}} & x_{N, k_{2}} & \ldots & x_{N, k_{n}} & x_{N, r_{1}} & x_{N, r_{2}} & \ldots & x_{N, r_{n}} & x_{N, v_{1}} & x_{N, v_{2}} & \ldots & x_{N, v_{n}}\end{array}\right]$

- $\beta=\left[\begin{array}{lllllllll}\beta_{0} & \beta_{1,1} & \ldots & \beta_{1, n} & \beta_{2,1} & \ldots & \beta_{2, n} & \beta_{3,1} \ldots & \beta_{3, n}\end{array}\right]^{T}$.

The $\beta$ values and regression analyses come from statistical software.

The regression analyses give the correlation coefficient which establishes the degree of relevance between the EPI indicator and the variables involved in the model. 
Tilca M., Mare E., Apatean A. (2018)

A model to measure the performance of human resources in organisations

Proposition 4. The correlation coefficient is the percentage of variation in the response EPI that is explained by the regression. The higher the value, the better the regression fits the data. The correlation coefficient is always between 0\% and $100 \%$.

Observation 3. It is known that multiple correlation coefficient always increases (or stays the same) as more independent variables are added to multiple linear regression model, even if the independent variables added are unrelated to the dependent variable (PennState, 2017). However, the multiple linear correlation may be applied to investigate how much EPI is related to the independent variables if there is used a larger sample of data corresponding to more than 40 predicted EPI values (MiniTab Express support, 2016).

\section{Findings}

In order to compute the value of the employee performance indicator and to determine the intensity of the relation between employee performance indicator and its variables, the statistical $R$ software is used. $R$ is a free and powerful environment language and software for statistical calculation and graphics which contains linear and non-linear modelling techniques. There is a variety of data types including vectors, matrices, lists and data windows. $\mathrm{R}$ provides facilities for implementing regressions using functions from $R$ packages. In (Tilca \& Bojor, 2016), $R$ was used to study the outcomes generated by three different types of regression: linear, spline and B-spline regression. Now we use $\mathrm{R}$ to implement the formula of EPI indicator and to interpret the multiple linear regression and correlation. A complex study about the correlation of the regression variables may be applied starting from the paper (Precup, 2015).

The $\mathrm{R}$ algorithm is described below.

Input data: $\mathrm{n}$ - the number of criteria

The $\mathrm{R}$ algorithm is described below.

Input data: $\mathrm{n}$ - the number of criteria

$$
\begin{aligned}
& c=(c[1] \quad \ldots \quad c[n])-\text { string vector of criteria }
\end{aligned}
$$

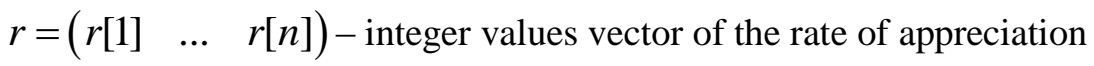

$$
\begin{aligned}
& v=\left(\begin{array}{lll}
v[1] & \ldots & v[n]
\end{array}\right)-\text { real values vector of the importance rate } \\
& k=\left(\begin{array}{lll}
k[1] & \ldots & k[n]
\end{array}\right)-\text { integer values vector of the number of the } \\
& \text { achievements }
\end{aligned}
$$

Output data: EPI - the employee performance indicator - real number

$\mathrm{Y}_{\mathrm{EPI}}$ - the predicted value of EPI - real number 
Tilca M., Mare E., Apatean A. (2018)

A model to measure the performance of human resources in organisations

$$
\mathrm{R}^{2} \text { - square multiple correlation coefficients }
$$

Step 1. Inserting the given values

Step 2. Computing the EPI using the weighted mean formula

Step 3. Computing the predicted values EPI using the multiple linear regression

Step 4. Computing the multiple correlation coefficient

Step 5. Displaying the results

The algorithm was implemented in $\mathrm{R}$, in ScriptCode. $\mathrm{R}$ file. The R-functions used in algorithm are:

\section{R-function}

cat ( "...")

readline (prompt $=\ldots, " \backslash \backslash, ")[[1]]$

as.numeric (.)

read.delin ("file.txt", is

header $=$ TRUE,

set $="$ ", , dec $="$ ". ")

lm ( $\mathrm{Y}$ model, data)

summery (model)

coefficients (model)

fitted (model)

runif $(\mathrm{n}, \min =m, \max =M)$

floor $(n)$
Used to

- print the information on-screen;

- read a line from the terminal;

- converting a factor to numeric;

- read in delimited files, where data

organized in data matrix with comaseparated elements which has header; - create a linear (simple or multiple) regression model given some formula, in the form of $\mathrm{Y} \sim \mathrm{X}$;

- summarise the results of model fitting functions;

- extract model coefficients;

- compute the predicted values of the model;

- generate random numbers with a uniform distribution;

- round a number.

The code from ScriptCode. $\mathrm{R}$ file is divided in four parts:

- first part implements the employee performance indicator EPI formula,

- second part implements the multiple linear regression model with data imported from text file,

- third part implements the multiple linear regression model with random data,

- forth part gives conclusions.

The Scriptcode. $\mathrm{R}$ file is called in $\mathrm{R}$ Console, by tasting source ("ScritCode. $R$ ") (the ScriptCode.R file has to be in the current working directory of the $\mathrm{R}$ process). Data input: the number of criteria, the number of achievements, the rate of appreciation and the rate of importance. The code computes the EPI value for input data. The interpretation of the employee 
Tilca M., Mare E., Apatean A. (2018)

A model to measure the performance of human resources in organisations

performance regarding the investigated criteria is displayed in the third part Conclusions.

$$
\text { EPI<-sum }(k \star r \star v) / \operatorname{sum}(k \star r)
$$

Figure 1. The code of the EPI computation

Source: the author's simulation in $\mathrm{R}$

Data input necessary in the second part of the code need to be organized in a simple ForRegression.txt file. The file must contains at least 10 different values of EPI corresponding to 10 employees evaluations. Data are organized in $10 \times 9$ matrix with elements comma separated. The data are loaded in $\mathrm{R}$ using the read.delim(.)function and used in regression formula $\operatorname{lm}($.$) and$ summary (.). Thus, the ScriptCode.R file returns the regression results: the values of regression coefficients ( $\beta$ vector), the predicted values of EPI ( $y$ vector), residual values of the predicted values ( $\varepsilon$ vector) and the correlation coefficient (multiple R-squared $R^{2}$ ).

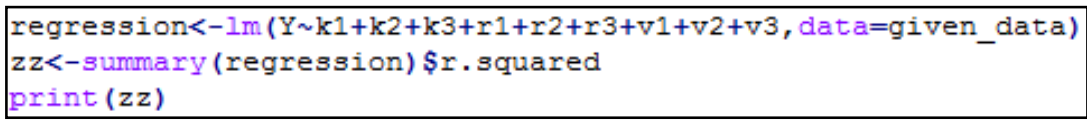

Figure 2. The code of the linear regression predicted values EPI and R-squared coefficient computation using given set of data*

Source: the author's simulation in $\mathrm{R}$

* Here, the $\operatorname{lm}($. ) function is applied for 9 independent variables

The third part uses data randomly generated. Considering a sufficiently large number of employees performance evaluations (between 40 and 90), the code will automatically compute the predicted EPI values and the correlation coefficient $R^{2}$ using random data.

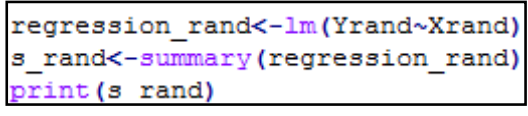

Figure 3. The code of the regression predicted values EPI and R-squared coefficient Source: the author's simulation in $\mathrm{R}$ computation using random data

Forth part of the code displays conclusions about

- the EPI value and the interpretation of the employee performance and

Studia Universitatis "Vasile Goldis" Arad. Economics Series Vol 28 Issue 1/2018 ISSN: 1584-2339; (online) ISSN: 2285 - 3065 
Tilca M., Mare E., Apatean A. (2018)

A model to measure the performance of human resources in organisations

- the degree of relevance between the EPI indicator and the variables involved in the model and the corresponding interpretation.

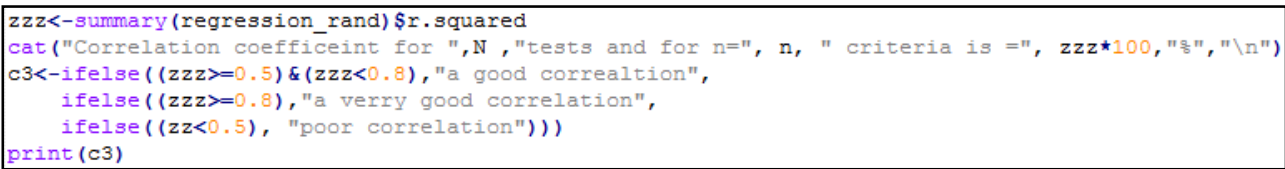

Figure 4. The code of the $R$-squared interpretation

Source: the author's simulation in $\mathrm{R}$

\section{Conclusions}

The evaluation of the employee performance is a constant concern for human resources department. The managers are searching to improve the criteria of measuring employees' performance and the software developers are having difficulty finding the concrete formula that measures performance in various situations.

The solution proposed in this article measures human resources performance. The employee performance indicator (EPI) is based on the defined performance criteria of each job together with numerical values: the number of achievements, the rate of appreciation and the rate of importance for each criterion. The question is how well EPI formula is defined? Are the variables and EPI sufficiently related? An algorithm of multiple linear regression computation is implemented in $\mathrm{R}$ in order to indicate the association between dependent variable EPI and independent variables. Applying the ScriptCode.R file we obtain the following conclusions:

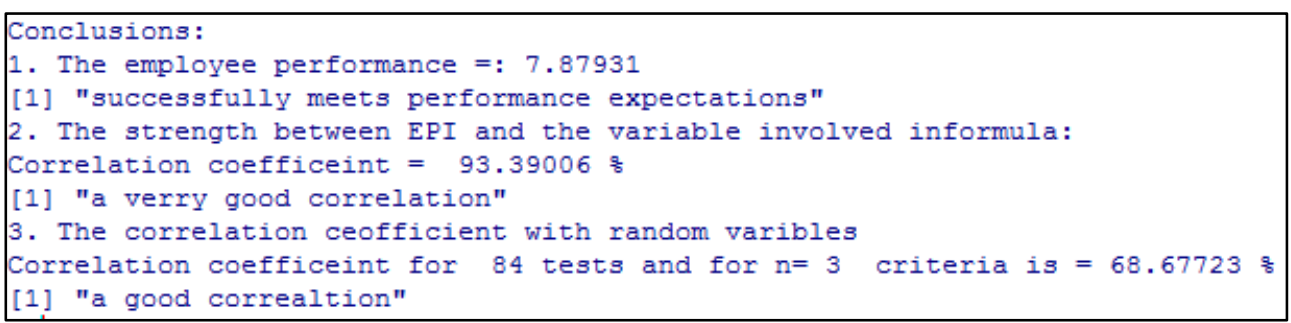

Figure 5. The interpretations of the results

Source: the author's simulation in $\mathrm{R}$

1. for the same values as in previous section, the employee performance indicator EPI is 7.88 (the rounded of 7.87931);

2. for the same values as in previous section, the multiple correlation coefficient between EPI and the variable involved in formula is R-squared 
Tilca M., Mare E., Apatean A. (2018)

A model to measure the performance of human resources in organisations

$=0.9339006$ a very good correlation; this means that $93.39 \%$ of the variation of the EPI indicator is explained by the variation of the variables (here 9 variables were considered: each of three criterion has three variables);

3. for random generated values of the number of evaluated employees $N$, the number of criteria $n$ and the values for variables $k, r, v$, the multiple correlation coefficient between EPI and the variable involved in formula, $\mathrm{R}$-squared $=0.6867723$ a good correlation; this means that $68.67 \%$ of the variation of the EPI indicator is explained by the variation of the variables (here $\mathrm{n} \times 3$ variables were random generated); the generated number of the experiments (evaluated employees number) is 84 and 3 criteria.

Other elements of the regression analysis are:

- the residuals of the predicted EPI values vary between -0.7439 and $0.71-$ very good predictions;

- the residual standard error 1.696 being small indicates that the regression equation is relevant

- p-value 0.5547>0.05 indicates that the predicted EPI are not statistical significant, but a large number of data will generate more trusted predicted values; thus, for 84 observed data and the 3 criteria, the predicted EPI values are significant because $\mathrm{p}$-value is $6.938 \mathrm{e}-08$.

Following these results, the variables (the number of achievements, the rate of appreciation and the rate of importance for each criterion) involved in EPI formula are important (significant) in the definition of employee performance indicator. Thus, the EPI indicator, continuously evaluated, may be considered a HR performance indicator in ongoing performance management.

\section{Notes}

[1] Bersin by Deloitte delivers research-based people strategies designed to help leaders drive exceptional business performance http://www.bersin.com

[2] Chief Learning Officer - a multimedia publication focused on the importance, benefits and advancements of a properly trained workforce http://www.clomedia.com

[3] A-team - an enterprise goals \& continuous performance management platform www.atiim.com

[4] Step two - site for planning and designing solution for the workplace and workforce http://www.steptwo.com.au

[5] High-Potential Employee is an individual with ability, aspiration and engagement to rise to and succeed in more senior, critical positions.

[6] HRIS is known as HRMS - Human Resource Management Systems or HCM - Human Capital Management software 


\section{References}

1. Adnan, S. \& Mohamed, Y., 2014. Performance Evaluation - Methods and Techniques Survey. International Journal of Computer and Information Technology, 3(5), pp. 966979.

2. Armstrong, M. \& Baron, A., 1998. Performance Management Handbook. London: IPM.

3. Atiim, 2017. Learn About Goals Setting, OKR framework and Team Performance. [Online] Available at: https://www.atiim.com/resources/

[Accessed 30 September 2017].

4. Brandon Hall Group, 2015. The Value of Ongoing Performance Managemen. [Online] Available at: http://www.iitd.ie/Portals/0/Knowledge\%20Centre/The-Value-ofOngoing-Performance-Manangement.pdf [Accessed 30 September 2017].

5. Gandhi, V., 2017. Managers, Get Ready for Ongoing Performance Conversations. [Online] Available at:

http://www.clomedia.com/2017/05/31/managers-get-ready-ongoing-performanceconversations/ [Accessed 30 September 2017].

6. Garr, S., 2011. The Performance Management Framework: Evolving Performance Management to Fit the Modern Workforce. [Online] Available at: http://www.bersin.com/News/Details.aspx?id=14208 [Accessed 30 September 2017].

7. Hansen, J., 2017. Why Ongoing Feedback vs. Annual Performance Reviews?. [Online] Available at: https://www.atiim.com/blog/why-ongoing-feedback-vs-annualperformancereviews/?utm campaign=PERFORMANCE\%20content\%20to\%20demo\&utm source= hs automation\&utm medium $=$ email\&utm content $=33636862 \&$ hsenc $=p 2 A N q t z-$ DNnMuDLSywt0dwSKqF2mrtWs8jIH1KSuQ-TfOuzMOLAMX7PZ8p [Accessed 5 Octomber 2017].

8. Hearn, S., 2016. What is Continuous Performance Management?. [Online] Available at: https://clearreview.com/continuous-performance-management/ [Accessed 5 October 2017].

9. Hervé, A., 2007. Multiple Correlation Coefficient. In: A. Hervé, ed. Encyclopedia of Measurement and Statistics. Dallas: Neil Salkind Ed..

10. CAEW, 2017. Employee key performance indicators (KPI). [Online] Available at: http://www.icaew.com/technical/business-performance-managementcommunity/data-and-kpis/kpi-library/employee-kpis [Accessed 2 October 2017]

11. MiniTab Express support, 2016. Interpret the key results for Multiple Regression. [Online] Available at: http://support.minitab.com/en-us/minitab-express/1/help-andhow-to/modeling-statistics/regression/how-to/multiple-regression/interpret-theresults/key-results/ [Accessed 11 October 2017].

12. O’Brien, J. \& Marakas, G., 2007. Management information systems. A business unit of The McGraw-Hill Companies, Volume McGraw-Hill/Irwin.

70 DE GRUYTER OPEN
Studia Universitatis "Vasile Goldis" Arad. Economics Series Vol 28 Issue 1/2018 ISSN: 1584-2339; (online) ISSN: $2285-3065$

Web: publicatii.uvvg.ro/index.php/studiaeconomia.Pages $57-73$ 
Tilca M., Mare E., Apatean A. (2018)

A model to measure the performance of human resources in organisations

13. OPM.gov, 2016. Performance Management - Measuring. [Online] Available at: https://www.opm.gov/policy-data-oversight/performancemanagement/measuring/\# [Accessed 6 October 2017].

14. PennState, 2017. The Multiple Linear Regression Model. [Online] Available at: https://onlinecourses.science.psu.edu/stat501/node/311 [Accessed 4 October 2017].

15. Precup, M., 2015. What Drives Private Equity Investiments In R. Studia Universitatis "Vasile Goldis" Arad Economics Series, 25(4), pp. 25-42.

16. Prodan, A. \& Aruștei, C., 2015. Managementul resurselor umane. [Online] Available at:

https://portal.feaa.uaic.ro/balti/PublishingImages/Pages/default/Suport_curs_MRU.pdf

17. Rațiu-Suciu, C., Luban, F., Hîncu, D. \& Cicoiu, N., 2009. Modelare economică. București: Editura ASE.

18. Rietsema, D., 2016. Understanding HRIS, HRM, HCM. [Online] Available at: https://www.hrpayrollsystems.net/understanding-hris-hrms-hcm/ [Accessed 2 October 2017].

19. Robertson, J., 2005. 10 principles of effective information management. [Online] Available at: http://www.steptwo.com.au/papers/kmc effectiveim/ [Accessed 30 September 2017].

20. Rouse, M., 2016. Continuous performance management. [Online] Available at: http://searchhrsoftware.techtarget.com/definition/continuous-performancemanagement [Accessed 2 October 2017].

21. Tilca, M. \& Bojor, M., 2016. Comparative study of different types of regression applied to unemployment in Maramures County of Romania. Studia Universitatis "Vasile Goldis" Arad. Economics Series , 26(3), pp. 44-61.

22. UC Riverside, 2016. Performance Factors \& Behavior Indicators, California: Human Resources - University of California.

23. wikiHow, 2016. How to Measure Performance. [Online] Available at: http://www.wikihow.com/Measure-Performance [Accessed 06.10.2017].

24. Wikipedia, $2016 . \quad$ Multiple correlation. [Online] Available at: https://en.wikipedia.org/wiki/Multiple_correlation [Accessed 08.10.2017].

\section{Appendix A}

Fig. A.1. Sample of input data

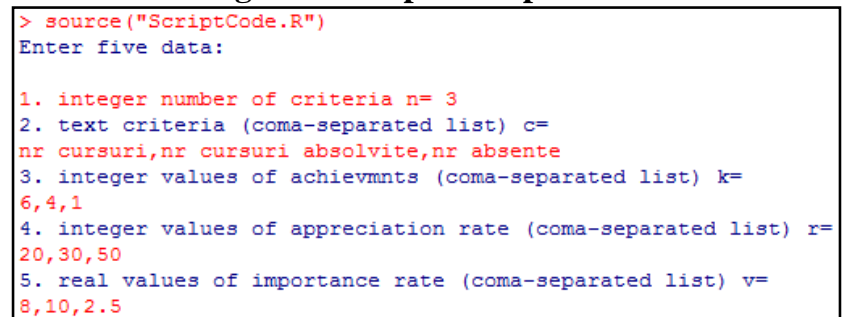

Source: own results generated by ScriptCode.R file

DE GRUYTER Studia Universitatis "Vasile Goldis" Arad. Economics Series Vol 28 Issue 1/2018 
Tilca M., Mare E., Apatean A. (2018)

A model to measure the performance of human resources in organisations

Fig.A.2. Sample of observed data from ForRegression. txt file

\begin{tabular}{|c|c|c|c|c|c|c|c|c|c|c|}
\hline \multicolumn{11}{|c|}{$>$ given_data } \\
\hline & EPI & $\mathrm{k} 1$ & k2 & k3 & r1 & $r 2$ & r3 & v1 & $\mathrm{v} 2$ & v3 \\
\hline 1 & 7.052 & 6 & 4 & 1 & 20.0 & 30.0 & 50.0 & 10.0 & 7.0 & 0.10 \\
\hline 2 & 7.083 & 2 & 2 & 3 & 35.0 & 40.0 & 70.0 & 10.0 & 10.0 & 5.00 \\
\hline 3 & 2.163 & 5 & 2 & 23 & 10.0 & 25.0 & 35.0 & 7.0 & 8.0 & 1.50 \\
\hline 4 & 3.602 & 14 & 6 & 22 & 40.0 & 79.0 & 95.0 & 10.0 & 9.5 & 0.55 \\
\hline 5 & 4.538 & 6 & 2 & 0 & 11.0 & 9.0 & 30.0 & 5.0 & 2.0 & 7.00 \\
\hline 6 & 5.085 & 22 & 13 & 42 & 6.4 & 6.3 & 4.2 & 9.0 & 5.0 & 2.00 \\
\hline 7 & 8.087 & 1 & 1 & 0 & 12.0 & 11.0 & 4.2 & 10.0 & 6.0 & 2.00 \\
\hline$\beta$ & 2.024 & 8 & 0 & 23 & 47.0 & 29.0 & 78.0 & 5.0 & 7.0 & 1.40 \\
\hline 9 & 7.298 & 23 & 14 & 7 & 20.0 & 13.0 & 50.0 & 9.5 & 10.0 & 3.00 \\
\hline 10 & 5.502 & 4 & 7 & 3 & 76.0 & 34.0 & 65.0 & 8.0 & 6.0 & 1.00 \\
\hline 11 & 4.000 & 0 & 2 & 0 & 45.0 & 76.0 & 43.0 & 3.0 & 4.0 & 2.00 \\
\hline
\end{tabular}

Source: own results generated by ScriptCode. $\mathrm{R}$ file

Fig.A.3. Multiple linear regression analysis using given set of data

Residual standard error: 1.696 on 1 degrees of freedom
Multiple R-squared: $0.9339, \quad$ Adjusted R-squared: 0.339
F-statistic: 1.57 on 9 and 1 DF, p-value: 0.5547

Source: own results generated by ScriptCode. $\mathrm{R}$ file

Fig.A.4. Multiple linear regression analysis using random set of data

Residual standard error: 0.8241 on 59 degrees of freedom
Multiple R-squared: 0.6868 , Adjusted R-squared: 0.5594
F-statistic: 5.39 on 24 and 59 DF, p-value: 6.938 - 08

Source: own results generated by ScriptCode. $\mathrm{R}$ file

Fig.A.5. Code of the EPI computation with data read from terminal

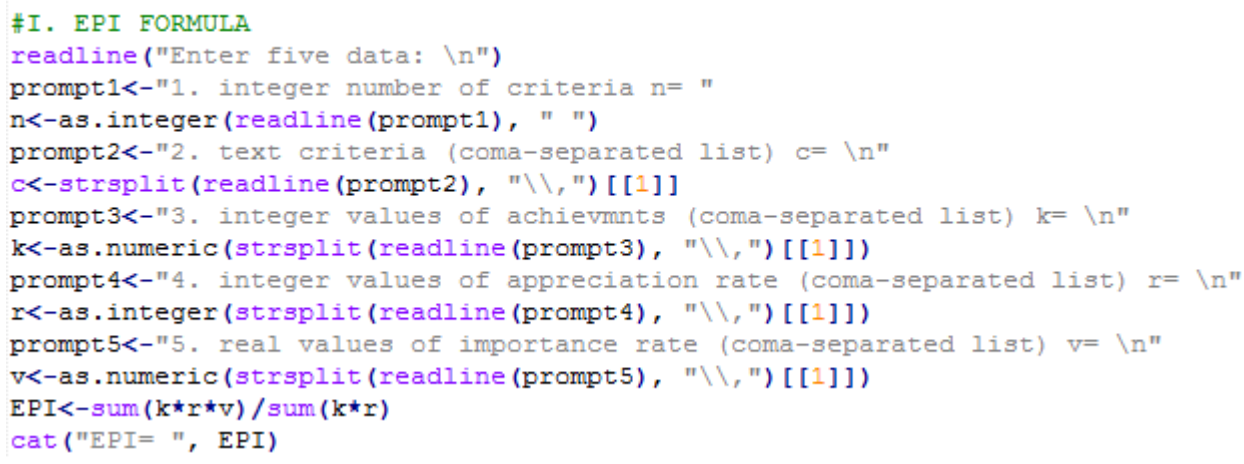

Source: own results generated by ScriptCode. $\mathrm{R}$ file 
Tilca M., Mare E., Apatean A. (2018)

A model to measure the performance of human resources in organisations

Fig.A.6. Code for the multiple regression/correlation with imported data

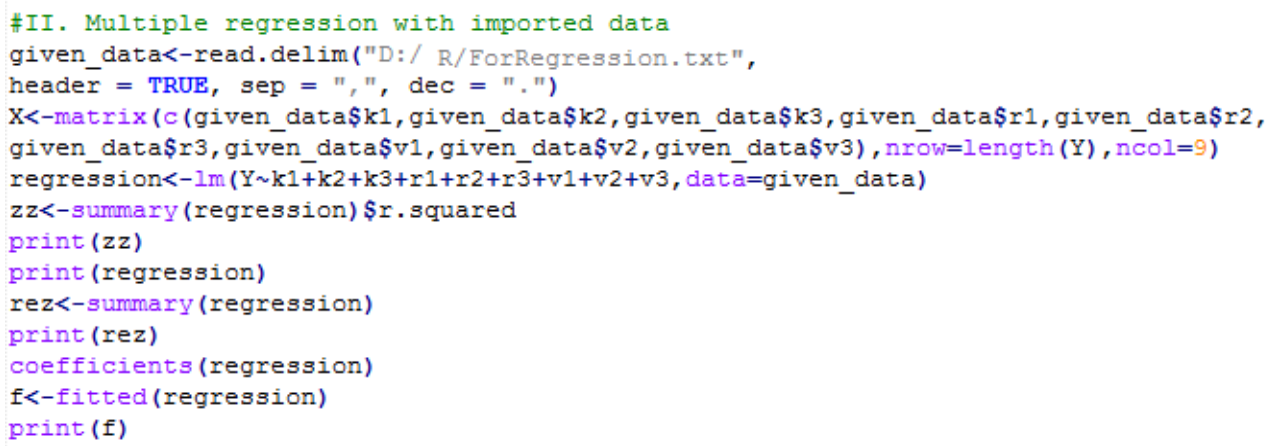

Source: own results generated by ScriptCode. R file

Fig.A.7. Code for the multiple regression/correlation with random data

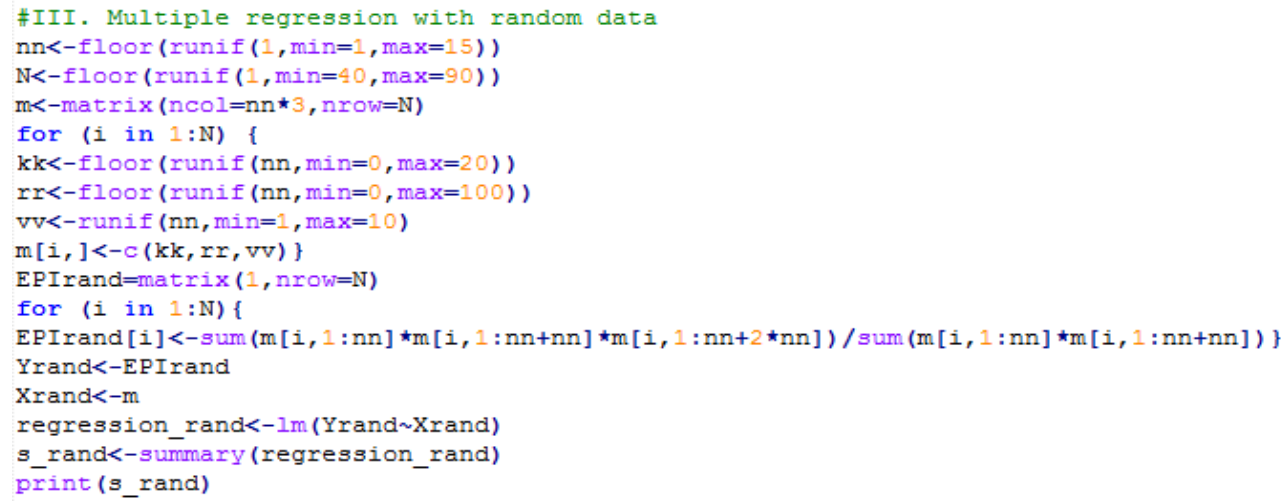

Source: own results generated by ScriptCode. R file

Studia Universitatis "Vasile Goldis" Arad. Economics Series Vol 28 Issue 1/2018 ISSN: 1584-2339; (online) ISSN: $2285-3065$

Web: publicatii.uvvg.ro/index.php/studiaeconomia.Pages $57-73$ 